\title{
Molecular Testing for Toxoplasma Diagnosis in Aborted Fetuses- Taleghani Maternity Hospital- Arak- Iran
}

\author{
Zahra Eslamirad ${ }^{1}$, Mahdi Mosayebi ${ }^{1 *}$, Reza Hajihossein ${ }^{1}$ \\ ${ }^{1}$ Department of Parasitology, Arak University of Medical Sciences, Arak, Iran.
}

\section{Received: 5 Feb 2014}

Revised : 28 Feb 2014

Accepted: 15 Mar 2014

Corresponding Authors: Mahdi Mosayebi Associate Professor, Department of Parasitology, Arak University of Medical Sciences, Arak, Iran. Phone: +98-8634173502-8

E-mail: m.mosayebi@arakmu.ac.ir

\begin{abstract}
Background: The diagnosis of toxoplasmosis is most critical in pregnant women who acquire infection during gestation and also in fetuses and newborns who are congenitally infected. This study described the performance of molecular and confirmatory serologic testing for toxoplasma infection in the tissues of human spontaneous aborted fetuses and their mothers' blood.

Material and Methods: 87 random samples from the tissues of body of spontaneous aborted fetuses (less than 14 weeks) in a separate container of preservative solution were collected from the delivery room of the university maternity hospital, Arak- Iran, during autumn 2012 to 2013. In the ward, $3 \mathrm{ml}$ of blood sample of their mothers were collected and the sera were separated and analyzed by ELISA method for the detection of specific IgG. DNA extraction from the tissues of fetuses was performed and stored until use. The PCR reaction was performed by a pair of primers. PCR products were analyzed by electrophoresis and stained with safe stain. It is necessary to mention first that the written consent was obtained from their mothers and after recovery, a demographic questionnaire was completed.

Results: Most of the mothers were 20-29 years of age and the correlation between the location of residence, contact with cats and eating undercooked food with abortion, not significant. Serological tests on the sera of 87 mothers for antiToxoplasma IgG showed $39.08 \%$ positive results. The results of PCR amplification showed that none of the 87 samples from aborted fetuses were infected with Toxoplasma gondii.

Conclusions: In aborted fetuses, we did not observe any evidence of Toxoplasmosis and it appears that Toxoplasma gondii was not the cause of spontaneous abortion in this area of Iran but considering the importance of the infection during pregnancy, the control measurements during pregnancy is required.
\end{abstract}

Keywords: Toxoplasma gondii; Abortion; Fetus

Please cite this article as: Eslamirad Z, Mosayebi M, Hajihossein R. Molecular Testing for Toxoplasma Diagnosis in Aborted Fetuses- Taleghani Maternity Hospital- Arak- Iran. Res Mol Med. 2014; 2 (3): 36-40

\section{Introduction}

If women become infected with $\mathrm{T}$. gondii during pregnancy, the parasite can cause abortion or seriously damage the fetus (1). The risk of intrauterine infection of fetus depends on the time of maternal infection during pregnancy, the immunological competence of mother during parasitaemia, the number and virulence of parasites transmitted to the fetus, and the age of fetus at the time of transmission. If not treated, the risk of intrauterine infection of the fetus increases during pregnancy $(2,3)$. The transmission risk of parasite to the fetus increases with increasing gestational age. But the disease severity and harms for infants are greater in early pregnancy (4). Toxoplasmosis causes abortion, but abortion due to toxoplasmosis is unclear in many areas where acquired toxoplasmosis is high. The risk of Toxoplasma infection in healthy pregnant women and reactivation of latent toxoplasmosis in 
infected pregnant women is high. The prevalence of toxoplasmosis in pregnant women is about $38 \%$ (based on IgG anti-toxoplasma) in Arak City, so abortion due toxoplasmosis may be significant in this region(5). In the present study, the role of Toxoplasma gondiiinabortioninhuman wasevaluated by molecular method and confirmatory serologic testing in Arak city (central province).

DNA detection is faster than isolation and can be Considered as a useful technique for diagnosingpathogens such as Toxoplasma gondii (6).

\section{Materials and Methods}

87 random samples from the tissues of body of spontaneous aborted fetuses (less than 14 weeks) were studied. Samples in a separate container of preservative solution were collected from the delivery room of the university maternity hospital, Arak- Iran during autumn 2012 to 2013.

At first, written consent was obtained from their mothers and after recovery, a demographic questionnaire was completed. In the ward, $3 \mathrm{ml}$ of blood sample of their mothers were collected and sera were separated by centrifugation at room temperature. These sera were tested by ELISA for the detection of specific anti-Toxoplasma IgG. The ELISA kits were provided by Pishtaz Teb CO. LTD., Iran. The procedure was performed according to the manufacturer's instructions.

The DNA extraction was performed by DNA extraction kit. This kit was provided by STRATEC Molecular (former Invitek $\mathrm{GmbH}$ ), Germany. The procedure was performed according to the manufacturer's instructions. The extract DNA was stored at $4{ }^{\circ} \mathrm{C}$ until use. The PCR reaction was performed by a pair of primers:

TOX4 (5'-CGCTGCAGGGAGGAAGACGAAAGT TG-3') Tox5 (5'-CGCTGCAGACACAGTGCATCT GTT-3')

The target of PCR was the $529 \mathrm{bp}$ fragment of the highly conserved 35 fold repetitive B1 gene (AF179871). The final reaction volume was $25 \mu \mathrm{l}$. The amplification was performed for $5 \mathrm{~min}$ at $94{ }^{\circ} \mathrm{C}$ initial step, followed by 35 cycles: denaturation for $30 \mathrm{~s}$ at $95{ }^{\circ} \mathrm{C}$, annealing for $30 \mathrm{~s}$ at $58{ }^{\circ} \mathrm{C}$ and extension for $30 \mathrm{~s}$ at $72^{\circ} \mathrm{C}$. PCR products were analyzed by electrophoresis in $1.5 \%$ agarose gel and stained with safe stain.

\section{Results \& Discussion}

Serological tests on the sera of 87 mothers showed that $39.08 \%$ of them had anti-Toxoplasma antibody. The demographic characteristics of mothers who had abortion are shown in Table 1.

The results of PCR amplification showed that none of the 87 samples from aborted fetuses were infected with T. gondii (Figure 1).

In the current study, the main objective was to determine the toxoplasmic infection in aborted fetuses and their mothers. Molecular method was performed for detecting T. gondii. $39.08 \%$ of mothers had anti-Toxoplasma antibody (IgG).

\begin{tabular}{llll} 
Table 1. Demographic characteristics of mothers who had abortion. \\
\hline Variable & & N & $\%$ \\
\hline \multirow{2}{*}{ Age (year) } & $20-29$ & 41 & 47.12 \\
& $30-39$ & 32 & 36.78 \\
& $>40$ & 14 & 16.09 \\
Habitat & Urban & 52 & 59.77 \\
& Rural & 36 & 40.23 \\
Keeping cat & Yes & 4 & 4.6 \\
& No & 83 & 95.4 \\
Eating undercooked food & No & 34 & 39.08 \\
& & 53 & 60.02 \\
\hline
\end{tabular}

The seroprevalence of toxoplasmosis based on IgG among pregnant women in Iran is relatively high (7). This rate in Zahedan, southeast of Iran, was reported to be $27 \%$ while in the northern part of the country was $48.3 \%$ (based on $\mathrm{IgG}$ ) (8). In central province (Arak), the prevalence of toxoplasmosis in pregnant women was about $38 \%$ (7).

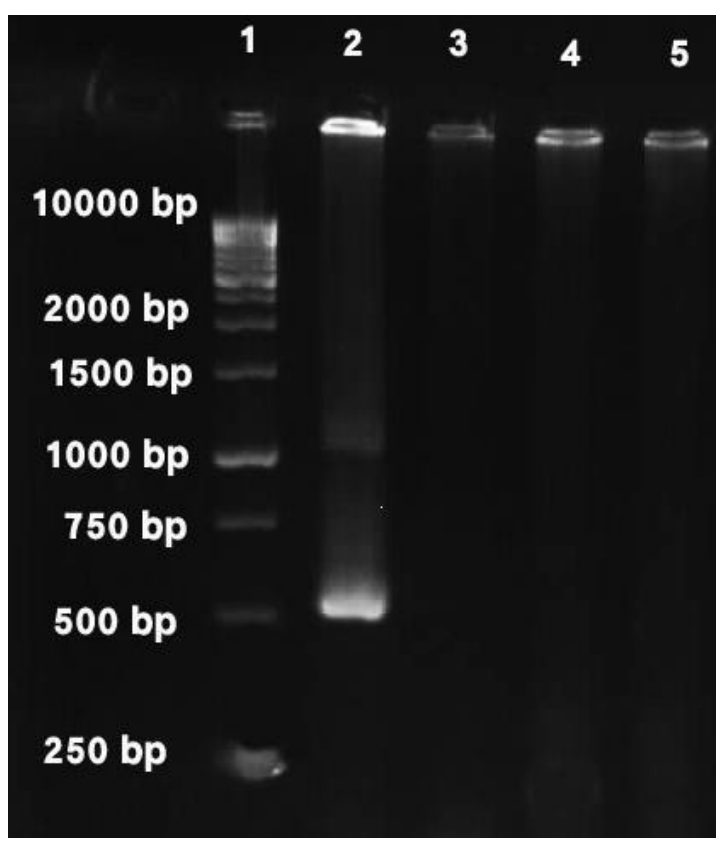

Figure 1. PCR products of aborted fetuses' samples on agarose 1\%. Lane 1, molecular weight marker $1 \mathrm{~kb}$; Lane 2, Positive control; Lane 3, negative control; Lanes 4, 5 aborted fetus samples

In Shiraz, southern Iran, the seroprevalence of toxoplasmosis among pregnant women was reported to be $77.2 \%$ (9). This rate is lower in high school girls in Shiraz (11). 
In a study on pregnant women in New York, $0.6 \%$ of mothers acquired Toxoplasma during pregnancy and $13 \%$ of their infants were born with congenital toxoplasmosis. So, the rate of congenital toxoplasmosis was reported to be 7 per 10,000 live births (7).

A study in Colombia showed that 61 out of 15,333 umbilical cord blood samples have specific IgM for anti-Toxoplasma. This contributed a rate of 39 per 10,000 live births for congenital toxoplasmosis in this area (11). A study on the seroprevalence of toxoplasmosis in Kosovo in pregnant women demonstrated that $1.2 \%$ of women acquired toxoplasmosis during their pregnancy (12).

In our study, the rate of Toxoplasma infection in aborted fetuses was $0 \%$. But the result of research of Asgari et al. on aborted human placenta in Shiraz showed that the rate of Toxoplasma infection in aborted placenta was $14.4 \%$. (4). In one study by Sarkari et al., no parasite cyst or tachyzoites were detected in PCR positive sample by immunohistochemistry in 50 aborted fetuses in Shiraz, Iran. This might have contributed to the low level of parasite in the aborted tissues (13). In livestock, the results indicate that $T$. gondii DNA was the most frequently detected in ovine fetuses (18.1\%) (14).

The detection of Toxoplasma DNA in placental tissue may not exclusively be connected to abortion because it may be the parasite that enters the placenta but not the fetus. Moreover, all items such as type of sample, method of sampling, and size of sample may affect the outcome of research, as was observed in this study. In addition, the sensitivity of PCR is significantly higher when maternal infection occurs between 17 and 22 weeks'gestation (15), whereas in our research, the fetuses were under 14 weeks.

However, false-positive and false-negative tests do occur with PCR (16).A negative PCR at any gestation cannot completely rule out congenital infection, and obstetric providers should consider continued followup via serial ultrasounds, prophylaxis with spiramycin therapy, and neonatal testing (15). In this study, we did not find evidence of Toxoplasmosis trace in aborted fetuses, and it appears that Toxoplasma was not the cause of spontaneous abortion in this area of Iran in less than 14 weeks, but considering the importance of the infection during pregnancy, control measures during pregnancy are required.

\section{Acknowledgments}

We thank the Research Deputy of Arak University for the support. This work was supported by Arak University of Medical Sciences financially supported this research (Project number 621).

\section{Conflict of Interest}

The authors declare that there is no conflict of interest.

\section{References}

1. Remington JS, McLeod R, Thulliez P, Desmonts G. Infectious Diseases of the Fetus and Newborn Infant (Sixth Edition). Philadelphia: W.B. Saunders; 2006. p. 947-1091.

2. Torgerson PR, Mastroiacovo P. The global burden of congenital toxoplasmosis: a systematic review. Bull World Health Organ. 2013; 91(7):501-8. PMID: 23825877

3. Weiss LM, Dubey JP. Toxoplasmosis: A history of clinical observations. Int J Parasitol. 2009; 39(8):895-901. PMID: 19217908

4. Asgari Q, Fekri M, Monabati A, Kalantary M, Mohammadpour I, Motazedian MH, et al. Molecular Genotyping of Toxoplasma gondii in Human Spontaneous Aborted Fetuses in Shiraz, Southern Iran. Iran J Public Health. 2013; 42(6):620-5. PMID: 23967430

5. Vakil N, Mosayebi M, Kabirinia K, Sabouri S Seroepidemiology of toxoplasmosis in Pregnant Women refered to health and medical care centers of Arak. Iran. 7th National Congress on Zoonotic Diseases; 2011; Yasuj, Iran.

6. Masala G, Porcu R, Daga C, Denti S, Canu G, Patta C, et al. Detection of pathogens in ovine and caprine abortion samples from Sardinia, Italy, by PCR. J Vet Diagn Invest. 2007; 19(1):96-8. PMID: 17459840

7. Hajsoleimani F, Ataeian A, Nourian A, Mazloomzadeh S. Seroprevalence of Toxoplasma gondii in Pregnant Women and Bioassay of IgM Positive Cases in Zanjan, Northwest of Iran. Iran J Parasitol. 2012; 7(2):82-6. PMID: 23109950

8. Saeedi M, Veghari GR, Marjani A. Seroepidemiologic evaluation of anti-toxoplasma antibodies among women in north of Iran. Pak J Biol Sci. 2007; 10(14):2359-62. PMID: 19070157

9. Hatam G, Shamseddin A, Nikouee F. Seroprevalence of toxoplasmosis in high school girls in Fasa district, Iran. Iran J Immunol. 2005; 2:177-81.

10. Mostafavi SN, Ataei B, Nokhodian Z, Yaran M, Babak A. Seroepidemiology of Toxoplasma gondii infection in Isfahan province, central Iran: A population based study. J Res Med Sci. 2011; 16(4):496-501. PMID: 22091265

11. Rosso F, Les JT, Agudelo A, Villalobos C, Chaves JA, Tunubala GA, et al. Prevalence of infection with Toxoplasma gondii among pregnant women in Cali, Colombia, South America. Am J Trop Med Hyg. 2008; 78(3):504-8. PMID: 18337350

12. Dentico P, Volpe A, Putoto G, Ramadani N, Bertinato L, Berisha M, et al. Toxoplasmosis in Kosovo pregnant women. New Microbiol. 2011; 34(2):203-7. PMID: 21617833

13. Sarkari B, Asgari Q, Mirzaee S. Evaluation of immunohistochemistry and PCR in diagnosis of Toxoplasma infection in tissues of human aborted fetuses. Zahedan Res Med Sci. $2013 ; 15(12): 42$

14. Masala G, Porcu R, Madau L, Tanda A, Ibba B, Satta G, et al. Survey of ovine and caprine toxoplasmosis by IFAT and PCR assays in Sardinia, Italy. Vet Parasitol. 2003; 117(1-2):15-21. PMID: 14597274

15. Romand S, Wallon M, Franck J, Thulliez P, Peyron F, Dumon $\mathrm{H}$. Prenatal diagnosis using polymerase chain reaction on amniotic fluid for congenital toxoplasmosis. Obstet Gynecol. 2001; 97(2):296-300. PMID: 11165598 
16. Hohlfeld P, Daffos F, Costa JM, Thulliez P, Forestier F, Vidaud M. Prenatal diagnosis of congenital toxoplasmosis with a polymerase-chain-reaction test on amniotic fluid. N Engl J Med. 1994; 331(11):695-9. PMID: 8058075 